\title{
PENGARUH PENDEKATAN PENDIDIKAN MATEMATIKA REALISTIK INDONESIA (PMRI) TERHADAP HASIL BELAJAR MATEMATIKA SISWA KELAS III SD NEGERI 144 PEKANBARU
}

\author{
Helga Tri Gustina, Syahrilfuddin, Eddy Noviana \\ Pendidikan Guru Sekolah Dasar FKIP Universitas Riau \\ Helgatrigustina12@yahoo.com,syahrilfuddin@lecturer.unri.ac.id, \\ eddy.noviana@lecturer.unri.ac.id
}

\begin{abstract}
This study aims to determine the differences and increase in mathematics learning outcomes of third grade students of Pekanbaru Pekanbaru Elementary School between before (pretest) and after (posttest) applying the Indonesian Realistic Mathematics Education Approach (PMRI). The research method used was an experiment with the research design of one group pretest-posttest. This research was conducted in class III of SD Negeri 144 Pekanbaru in the odd semester of the 2018/2019 academic year on material money math subjects. The research subjects were class III students, amounting to 21 people. Data on mathematics learning outcomes were collected using a test technique in the form of a multiple choice objective test. Based on the results of data analysis and discussion, it can be concluded that there are differences and improvements in mathematics learning outcomes of Grade III students of Pekanbaru Pekanbaru Elementary School between before (pretest) and after (posttest) applying the PMRI approach. This is proven based on the results of data analysis obtained in the study. This difference is based on the results of the $t$ test. Obtained tcount fulfills the criteria of $t$ count $>t$ table or $4.5881>2.0423$. with the average $N$-Gain of 0.38 included in the medium category with. This shows that Ho is rejected and $\mathrm{Ha}$ is accepted, meaning there are differences and improvements in student learning outcomes. Based on the evidence it can be concluded that implementing Indonesian Realistic Mathematics Education (PMRI) has a positive influence on the results of mathematics learning for third grade students of Pekanbaru Elementary School 144.
\end{abstract}

Keywords: cooperative by using a method index card match, science studies learning outcomes

\section{PENDAHULUAN}

Matematika merupakan ilmu dasar untuk mempelajari ilmu-ilmu yang lain. Pemahaman terhadap matematika dan konsep dalam matematika sangat diperlukandan harus dipahami dengan benar sejak dini. Suatu konsep disusun berdasarkan konsep-konsep sebelumnya, dan akan menjadi dasar bagi konsepkonsep sebelumnya, dan akan menjadi dasar bagi konsep-konsep selanjutnya, 
sehingga pemahaman yang salah terhadap suatu konsep, akan berakibat pada kesalahan pemahaman terhadap konsep-konsep selanjutnya. Maka perlu adanya seorang guru memfasilitasi siswa agar siswa dapat menemukan konsep matematika sendiri dan menanamkan dasar konsep matematika sehingga tersimpan dalam memori jangka panjang. Namun pada umumya proses pembelajaran yang dilaksanakan selalu berpusat pada guru bukan pada siswa sehingga hasil belajar siswa menjadi rendah.

Kenyataan yang terjadi pada siswa kelas III SD Negeri 144 Pekanbaru, siswa disuruh mendengarkan penjelasan guru dan siswanya hanya menerima penjelasan guru tersebut. Banyak siswa merasa bosan dengan pembelajaran matematika karena hanya mendengar penjelasan guru, kemudian siswa kurang menguasai konsep yang dijelaskan guru secara abstrak. Sebagian siswa masih pasif dalam pembelajaran. Guru hanya mengandalkan buku yang tidak semua anak bisa langsung memahaminya. Sebagai contoh pelajaran matematika siswa hanya menghapal rumusnya saja tanpa memahi konsep dasar materi tersebut.

Dari penjelasan di atas perlu adanya perbaikan dalam proses pembelajaran, salah satunya dengan mengimplementasi pendekatan pembelajaran yang menekakan pada keaktifan siswa dan mengembangkan potensi yang dimiliki siswa secara maksimal. Pendekatan pembelajaran yang dapat diterapkan dalam pembelajaran matematika adalah pendekatan pendidikan matematika realistik indonesia, karena memiliki kelebihan yaitu lebih memberikan pengertian yang jelas kepada siswa tentang keterkaitan matematika dengan kehidupan sehari-hari, dan dengan bimbingan guru siswa dapat menyelesaikan masalah matematikanya.

Sehubungan dengan latar belakang yang dikemukakan, peneliti melakukan penelitian tindakan kelas dengan judul "Pengaruh Pendekatan Pendidikan Matematika Realistik Indonesia (PMRI) Terhadap Hasil belajar Matematika Siswa Kelas III SD Negeri 144 Pekanbaru".

Gravemeijer dalam Komang Agus Wartawan (2014:45) mengatakan pendidikan matematika realistik indonesia (PMRI) merupakan suatu pendekatan yang digunakan dalam pembelajaran matematika yang dilaksanakan dengan menempatkan realitas dan pengalaman siswa sebagai titik awal pembelajaran. Namun menurut Melly Andriani (2013:13) pendidikan matematika realistik 
indonesia adalah sebuah pendekatan belajar matematika yang dikembangkan sejak tahun 1971 oleh sekelompok ahli matematika yang dikembangkan sejak tahun 1971 oleh sekelompok ahli matematika sekolah yang dilaksanakan dengan menempatkan realitas dan pengalaman siswa sebagai titik awal pembelajaran.

Senada dengan pendapat Desty Septianawati (2014:57) mengatakan bahwa pendidikan matematika realistik Indonesia merupakan salah satu pendekatan pembelajaran matematika yang berorientasi pada matematisasi pengalaman sehari-hari dan menerapkan matematika dalam kehidupan sehari-hari.

Langkah-langkah proses pembelajaran matematika dengan PMRI menurut Melly Andriani dan Mimi Hariyani (2013:50), sebagai berikut:

1. Memahami masalah kontekstual.

2. Menjelaskan masalah kontekstual.

3. Menyelesaikan masalah kontekstual.

4. Membandingkan dan mendiskusikan jawaban.

5. Menyimpulkan.

\section{METODE PENELITIAN}

Jenis penelitian ini adalah penelitian kuantitatif dengan metode eksperimen dengan menggunakan desain penelitian one group pretest-posttest design yakni membandingkan nilai pretest dengan nilai posttest di dalam satu kelas. Pada desain ini nantinya sampel akan diberi tes awal (pretest) dan test akhir (posttest) setelah diberi perlakuan (Fendrik,M. Elvina, 2018)

\begin{tabular}{|ccc|}
\hline $\mathrm{O}_{1}$ & $\mathrm{X}$ & $\mathrm{O}_{2}$ \\
Pretest & perlakuan & posttest \\
\hline
\end{tabular}

(Sumber: Sugiyono,2013:75)

Subjek penelitian ini adalah siswa kelas III SD Negeri 144 Pekanbaru yang berjumlah 21 orang. Untuk menentukan sample penelitian ini maka peneliti menggunakan teknik sampling jenuh, yaitu keseluruhan populasi dijadikan sample (Arikunto,2010).

Data yang dikumpulkan dalam penelitian ini diambil dari hasil pretest dan postest siswa. Soal pretest dan posttest yang digunakan dalam penelitian ini 
adalah soal yang sama. Data yang dikumpulkan dalam penelitian ini dilakukan dengan menentukan sumber data terlebih dahulu, jenis data, teknik pengumpulan data serta instrumen yang digunakan.

Teknik analisis data yang digunakan adalah 1) Memberikan skor jawaban siswa sesuai kunci jawaban; 2) Menghitung rata-rata skor pretest dan postest; 3) Menetukan nilai standar deviasi; 4) Menghitung varians; 5) Uji normalitas (kolmogorov smirnov); 6) Uji homogenitas; 7) Uji perbandingan (uji t); 8) Peningkatan kompetensi dengan indeks $\mathrm{g}$.

\section{HASIL DAN PEMBAHASAN}

\section{Hasil penelitian}

\section{Data Pretest dan Posttest}

Hasil tes awal (pretest) adalah kemampuan hasil belajar siswa terhadap materi uang dalam pembelajaran matematika SD Negeri 144 Pekanbaru, dimana siswa belum diberikan perlakuan dengan pendekatan PMRI. Hasil test awal (pretest) dapat dilihat pada tabel 1 berikut.

Tabel 1

Data Tes Awal (Pretest) Siswa Kelas III SD Negeri 144 Pekanbaru

\begin{tabular}{|c|c|c|c|c|c|c|}
\hline Data & $\begin{array}{c}\text { Jumlah } \\
\text { siswa }(\mathrm{n})\end{array}$ & $\begin{array}{c}\text { Rata-rata } \\
\overline{(x)}\end{array}$ & $\begin{array}{c}\text { Standar } \\
\text { Deviasi } \\
(\mathrm{s})\end{array}$ & $\begin{array}{c}\text { Varians } \\
\left(\mathrm{s}^{2}\right.\end{array}$ & $\begin{array}{c}\text { Nilai } \\
\text { Min }\end{array}$ & $\begin{array}{c}\text { Nilai } \\
\text { Max }\end{array}$ \\
\hline Pretest & 21 & 58,10 & 9,93 & 98,59 & 40 & 72 \\
\hline
\end{tabular}

Berdasarkan tabel 1 dapat diketahui bahwa rata-rata siswa sebelum tindakan (treatmen) adalah 58,10. Nilai maksimal adalah 72 dan nilai minimal adalah 40, serta Standar Deviasi 9,93, Varians 98,59. Sedangkan untuk data posttest dapat dilihat pada tabel dibawah ini :

Tabel 2

Data Tes Akhir (Posttest) Siswa Kelas III SD Negeri 144 Pekanbaru

\begin{tabular}{|c|c|c|c|c|c|c|}
\hline \multirow{2}{*}{ Data } & $\begin{array}{c}\text { Jumlah } \\
\text { siswa }(\mathrm{n})\end{array}$ & $\begin{array}{c}\text { Rata-rata } \\
\overline{(x)}\end{array}$ & $\begin{array}{c}\text { Standar } \\
\text { Deviasi }(\mathrm{s})\end{array}$ & $\begin{array}{c}\text { Varians } \\
\left(\mathrm{s}^{2}\right)\end{array}$ & $\begin{array}{c}\text { Nilai } \\
\text { Min }\end{array}$ & $\begin{array}{c}\text { Nilai } \\
\text { Max }\end{array}$ \\
\hline
\end{tabular}




\begin{tabular}{|l|c|c|c|c|c|c|}
\hline Posttest & 21 & 73,52 & 10,54 & 111,16 & 52 & 92 \\
\hline
\end{tabular}

Berdasarkan tabel 2 dapat diketahui bahwa rata-rata siswa setelah diberi perlakuan adalah 73,52 . Nilai maksimal adalah 92 dan nilai minimal adalah adalah 52, standar deviasi 10,54 serta varians 111,16.

\section{Uji Normalitas Skor Pretest dan Posstest}

Uji normalitas data ini dilakukan dengan menggunakan Kolmogorov-Smirnov. Uji normalitas digunakan untuk mengetahui normalitas data skor tes awal dan data skor akhir dengan perumusan hipotesis sebagai berikut :

$\mathrm{H}_{0} \quad$ : data berdistribusi normal

$\mathrm{H}_{1} \quad$ : data tidak berdistribusi normal

dengan kriteria pengujian :

Tolak $\mathrm{H}_{0} \mathrm{jika} \mathrm{a}_{\max }>\mathrm{D}_{\text {tabel }}$ dan

Terima $\mathrm{H}_{0} \mathrm{j} ; k a \mathrm{a}_{\max } \leq \mathrm{D}_{\text {tabel }}$

Pengujian hipotesis menggunakan taraf signifikan $\alpha=0,05$ dan $D_{\text {tabel }}=0,2870$ (untuk uji Kolmogorov-Smirnov sampel tunggal) dengan kriteria jika $a_{\max } \leq D_{\text {tabel }}$ maka $\mathrm{H}_{0}$ diterima dan disimpulkan data berdistribusi normal.

Adapun hasil perhitungan uji normalitas terhadap tes awal (pretest) dan tes akhir (posttest) dapat dilihat pada tabel 3 berikut:

\section{Tabel 3}

Hasil Uji Normalitas Pretest dan Posttest Hasil Belajar Matematika

\begin{tabular}{|c|c|c|c|c|}
\hline \multirow{2}{*}{ Tes } & \multicolumn{3}{|c|}{ Normalitas } & \multirow{2}{*}{ Keputusan } \\
\cline { 2 - 4 } & $\mathrm{N}$ & $\mathrm{a}_{\text {maks }}$ & $\mathrm{D}_{\text {tabel }}$ & \\
\hline Awal (pretest) & 21 & 0,1016 & 0,2870 & Normal \\
\hline Akhir(posttest) & 21 & 0,1189 & 0,2870 & Normal \\
\hline
\end{tabular}

Berdasarkan tabel 3. dapat diketahui bahwa skor awal (pretest) yaitu $\mathrm{a}_{\text {maks }}=$ 0,1016 dan $D_{\text {tabel }}=0,2870$ maka $a_{\text {maks }}<D_{\text {tabel }}$ sehingga berdistribusi normal. Skor tes akhir (posttest) yaitu $\mathrm{a}_{\text {maks }}=0,1189$ dan $\mathrm{D}_{\text {tabel }}=0,2870$ maka $\mathrm{a}_{\text {maks }}<\mathrm{D}_{\text {tabel }}$ sehingga berdistribusi normal. 


\section{Uji Homogenitas Skor Pretest dan Posttest}

Berdasarkan hasil uji normalitas, diketahui skor tes awal dan tes akhir siswa berdistribusi normal, maka langkah selanjutnya adalah melakukan uji homogenitas varians skor tes awal dan skor tes akhir. Pengujian homogenitas data dilakukan dengan teknik uji $\mathrm{F}$ (Fisher) dengan cara membandingkan varians data terbesar dan terkecil.

Perumusan hipotesis pengujian homogenitas varians data tes awal dan tes akhir pada penelitian ini adalah sebagai

$\mathrm{H}_{\mathrm{o}} \quad$ : Varians skor tes awal/tes akhir homogen

$\mathrm{H}_{\mathrm{a}}$ : Varians skor tes awal/akhir tidak homogen (tidak homogen)

Dengan tarif signifikan $\alpha=0,05$ maka di dapat $F_{\text {tabel }}$ adalah 2.12 dengan kriteria sebagai berikut:

Jika $F_{\text {hitung }}<F_{\text {tabel }}$, maka Ho diterima berarti varians homogen.

Jika $F_{\text {hitung }}>F_{\text {tabel }}$, maka Ho ditolak berarti varians tidak homogen.

Hasil perhitungan homogenitas varians skor tes awal dapat dilihat dalam tabel 4 berikut.

\section{Tabel 4}

Hasil Uji Homogenitas Skor TesAwal (Pretest) dan skor Tes Akhir (Posttest)

\begin{tabular}{|c|c|c|c|c|}
\hline \multirow{2}{*}{ Data } & \multicolumn{3}{|c|}{ Homogenitas } & \multirow{2}{*}{ Keputusan } \\
\cline { 2 - 3 } & Varians & $F_{\text {hitung }}$ & $F_{\text {tabel }}$ & \\
\hline Pretest & 98,590 & \multirow{2}{*}{1,275} & 2,12 & Homogen \\
\hline Posttest & 111,161 & & & Homogen \\
\hline
\end{tabular}

Berdasarkan tabel 4 dapat diketahui bahwa setelah dilakukan uji homogenitas pada skor tes awal dan tes akhir di dapatkan $F_{\text {hitung }}<F_{\text {tabel }}$ atau 1,275 $<2,12$. Hal ini berarti bahwa varians bersifat homogen atau dapat dilanjutkan dengan uji t.

\section{Uji t Pretest dan Posttest}


Untuk menganalisis perbedaan antara skor pretest dan posttest hasil belajar matematika menggunakan pretest dan posttest one grup design, maka dilakukan pengujian hipotesis komparasi dengan uji-t sebagai berikut :

$$
t=\frac{M d}{\sqrt{\frac{\Sigma x_{d}^{2}}{n(n-1)}}}, \text { (Supardi, 2013: 324) }
$$

dengan hipotesis sebagai berikut:

Tolak $\mathrm{H}_{0}$ jika $\mathrm{t}_{\text {hitung }}>\mathrm{t}_{\text {tabel }}$ dan

Tabel 5

Uji t skor pretest dan posttest

\begin{tabular}{|c|c|c|c|c|c|c|c|c|}
\hline$M_{d}$ & $\Sigma x^{2} d$ & $N$ & $d k(n-1)$ & $t_{\text {hitung }}$ & $a$ & $t_{\text {tabel }}$ & $\begin{array}{c}\text { Penolaka } \\
n\end{array}$ & $\begin{array}{c}\text { Kesimpula } \\
n\end{array}$ \\
\hline 15,43 & $\begin{array}{c}575 \\
3\end{array}$ & 21 & 20 & 4,5881 & 0,05 & 2,0860 & Tolak $\mathrm{H}_{0}$ & Signifikan \\
\hline
\end{tabular}

Berdasarkan tabel 5 dengan membandingkan $t_{\text {hitung }}$ dengan $t_{\text {tabel }}$, dengan $\alpha=$ 0,05 dan $\mathrm{dk}=20$, maka $t_{\text {tabel }}$ di konsultasikan dengan tabel distribusi $\mathrm{t}$ dengan $\mathrm{dk}=$ 20 , dengan demikian $t_{\text {tabel }}=2,0860$. Karena $t_{\text {hitung }}=11,421$ dan $t_{\text {tabel }}=2,0860$ maka disimpulkant ${ }_{\text {hitung }}>t_{\text {tabel }}$, maka tolak $H_{0}$ artinya signifikan. Ini berarti terdapat perbedaan signifikan skor perolehan tes awal (pretest) dengan tes akhir (posttest) setelah diberikan perlakuan dengan pendekatan PMRI.

\section{Analisis Hasil Peningkatan Pretest dan Posttest}

Besarnya peningkatan hasil belajar matematika sebelum dan sesudah perlakuan diberikan menggunakan pendekatan PMRI dihitung menggunakan rumus gain ternormalisasi. (Normalized Gain) .N-gain bertujuan untuk mengetahui peningkatan hasil belajar matematika sebelum dan sesudah perlakuan diberikan yaitu pendekatan PMRI. Adapun N-Gain hasil belajar matematika berjumlah 7,90, dengan rata-rata N-Gain sebesar 0,38 . Gain hasil belajar matematika siswa kelas III SD Negeri 144 Pekanbaru yang diperoleh 0,38 termasuk pada kategori sedang.

Hasil analisis peningkatan skor sebelum pembelajaran (pretest) dan sesudah pembelajaran (posttest) yang di peroleh dapat dilihat pada tabel 6 . 


\section{Tabel 6}

Analisis Hasil Peningkatan Pretest dan Posttest

\begin{tabular}{|c|c|c|c|}
\hline & Pretest & Posttest & Gain \\
\hline Jumlah & 1220 & 1544 & 7,90 \\
\hline Rata-rata & 58,09 & 73,52 & 0,38 \\
\hline
\end{tabular}

Berdasarkan tabel 6 dapat dilihat bahwa terjadi peningkatan skor hasil belajar siswa. Rata-rata skor tes awal (pretest) siswa 58,09 setelah diberi perlakuan yaitu dengan menerapkan pendekatan (PMRI) dan kemudian dilakukan tes akhir (posttest) rata-rata skor meningkat menjadi 73,52 dengan rata-rata indeks gain 0,38 kategori sedang.

\section{Pembahasan}

Penelitian ini menggunakan pendekatan PMRI. Data yang diperoleh dalam penelitian ini adalah data hasil tes awal (pretest), hasil akhir (posttest), peningkatan skor hasil belajar siswa SD Negeri 144 pekanbaru.

Penelitian ini bertujuan untuk melihat adanya perbedaan hasil belajar matematika siswa kelas III SDNegeri 144 Pekanbaru sebelum menerapkan pendekatan PMRI dengan sesudah menerapkan PMRI

Kelas III SD Negeri 144 Pekanbaru terdiri dari dua kelas, pada penelitian ini yang menjadi subjek penelitian adalah kelas IIIA yang berjumlah 21 orang. Pembelajaran dilaksanakan dengan 5 kali pertemuan. Pertemuan pertama melaksanakan tes awal (pretest), pertemuan kedua sampai pertemuan keempat menyampaikan materi pembelajaran. Setelah mengalami proses pembelajaran sebanyak tiga kali pertemuan dengan (PMRI) selanjutnya siswa diberikan tes akhir (posttest). Pemberian posttest bertujuan untuk mengetahui peningkatan hasil belajar siswa setelah diberikan perlakuan. 
Setelah mengalami proses pembelajaran sebanyak tiga kali pertemuan dengan menggunakan pendekatan PMRI, selanjutnya siswa diberikan test akhir (posttest). Pemberian posttest bertujuan untuk mengetahui perbedaan hasil belajar siswa setelah diberikan perlakuan dan seberapa besar peningkatan hasil belajar sebelum dan sesudah menerapkan pendekatan PMRI terhadap hasil belajar.

Hasil analisis terhadap skor posttest memiliki peningkatan rata-rata dari 58,10 dengan standar deviasi 9,93 menjadi 73,52 dengan standar deviasi 10,54. Berdasarkan perbedaan rata-rata pottest tersebut dapat dilihat bahwa terdapat perbedaan hasil belajar siswa setelah menerapkan PMRI. Perbedaan ini didasarkan pada hasil uji $t$. Diperoleh $t_{\text {hitung }}$ memenuhi kriteria $t_{\text {hitung }}>t_{\text {tabel }}$ atau $4,5881>2,0423$. Hal ini menunjukkan Ho ditolak dan Ha diterima berarti terdapat perbedaan hasil belajar siswa yang signifikan.

Setelah dilakukan pretest dan posttest untuk mengetahui peningkatan skor hasil belajar siswa maka dilakukan analisis peningkatan skor sebelum dan sesudah perlakuan yang dihitung dengan uji gain ternormalisasi. Dari analisis terhadap skor gain ternormalisasi memiliki rata-rata 0,38 kategori sedang dengan standar deviasi 0,182.

Perbedaan peningkatan hasil belajar siswa antara pretest dan posttest disebabkan karena perlakuan yang diberikan yaitu dengan menggunakan pendekatan PMRI. Hal tersebut terjadi karena dengan pendekatan PMRI memberikan pengertian yang jelas mengenai keterkaitan antara matematika dengan kehidupan sehari-hari, pembelajaran PMRI juga memberikan pengertian yang jelas dan operasional kepada siswa, proses pembelajaran merupakan suatu yang utama dan untuk mempelajari matematika seseorang harus menjalani proses itu dan berusaha menemukan sendiri konsep-konsep matematika dengan bantuan pihak yang lebih ${ }^{-}$tahu (gurū kemudian pendekatan PMRI ini dapat dikembangkan sendiri oleh siswa,dan pendekatan PMRI pemecahan suatu soal atau masalah tidak harus tunggal dan tidak harus sama satu sama lain. Setiap orang bisa menemukan atau menggunakan cara sendiri, asalkan orang itu bersungguh-sungguh dalam mengerjakan soal atau masalah tersebut sehingga pendekatan PMRI dapat meningkatkan hasil belajar matematatika. 


\section{SIMPULAN}

Menurut hasil analisis data dan pembahasan yang telah dilaksanakan dapat kita ambil kesimpulan bahwa terdapat perbedaan hasil belajar siswa dan peningkatan hasil belajar siswa sebelum menerapkan PMRI dengan sesudah menerapkan PMRI. Hal ini dibuktikan berdasarkan hasil analisis data yang diperoleh dalam penelitian. Perbedaan ini didasarkan pada hasil uji t. Diperoleh $t_{\text {hitung }}$ memenuhi kriteria $t_{\text {hitung }}>t_{\text {tabel }}$ atau 4,5881 $>2,0423$. dengan rata-rata $N-G a i n$ sebesar 0,38 termasuk pada kategori sedang dengan. Hal ini menunjukkan Ho ditolak dan Ha diterima berarti terdapat perbedaan dan peningkatan hasil belajar siswa.

Berdasarkan bukti, dapat dapat disimpulkan bahwa menerpakan PMRI memberikan pengaruh yang positif terhadap hasil belajar matematika siswa siswi kelas III SD Negeri 144 Pekanbaru.

Berdasarkan simpulan dari hasil penelitian maka peneliti menyarankan beberapa hal, yaitu :

1. Untuk guru kelas, peneliti merekomendasikan untuk menerapkan PMRI sebagai alternatif agar dapat meningkatkan hasil belajar matematika siswa.

2. Kepada peneliti selanjutnya, agar penelitian ini dapat dijadikan sebagai dasar untuk melakukan penelitian dengan pendekatan yang lain yang lebih efektif untuk meningkatkan hasil belajar matematika siswa.

\section{DAFTAR PUSTAKA}

Andriani, Melly, Mimi Hariyani. 2013. Pembelajaran Matematika SD/MI. Benteng Media. Pekanbaru

Arikunto, Suharsimi. 2009. Manajemen Pengajaran Secara Manusiawi. Jakarta: Rineka Cipta.

Artawan,Komang Agus, dkk. 2014. Penerapan Pendekatan Pendidikan Matematika Realistik Indonesia untuk Meningkatkan Aktivitas dan Hasil Belajar Matematika Siswa kelas V SD. Jurnal Mimbar PGSD Universitas Pendidikan Ganesha. 2(1). Universitas Pendidikan Ganesha. Singaraja.

Fendrik, M. Elvina. 2018. The Impact of Visual Thinking Approach to Promote Elementary Students' Problem Solving Skill in Mathematics. Vol.1 No. 2, hlm 93-108. 
Septiana, Desti. 2014. Efektivitas Metode Diskusi dengan Pendekatan Realistik (PMR) ditinjau dari Tipe Kepribadian Siswa Kelas VIII SMP Negeri di Kabupaten Lampung Timur. Jurnal Pendidikan Matematika FKIP Univ. Muhammadiyah Metro. 3(2): 57. IKIP PGRI Pontianak.

Sugiyono. 2016. Metode Penelitian Pendidikan. Alfabeta. Bandung

Sundayana, Rostiana. 2014. Statistika Penelitian Pendidikan. Alfabeta. Bandung 